\title{
NUMERICAL APPROACHES FOR A MATHEMATICAL MODEL OF AN FCCU REGENERATOR
}

\begin{abstract}
J. C. Penteado,
C. O. R. Negrão

and L. F. S. Rossi ${ }^{\mathrm{b}}$

${ }^{a, b}$ Universidade Tecnológica Federal do Paraná

Departamento Acadêmico de Mecânica

Bairro Rebouças

CEP 80230-901, Curitiba, Paraná, Brasil

anegrao@utfpr.edu.br

1frossi@utfpr.edu.br

${ }^{\mathrm{a}}$ Corresponding author
\end{abstract}

\section{NOMENCLATURE}

$a-$ coefficient of the discretized equation (24) (-)

$A$ - heat transfer area $\left(\mathrm{m}^{-2}\right)$

$C$ - molar concentration $\left(\mathrm{kmol} \mathrm{kg}^{-1}\right)$

$c_{p}$ - specific heat $\left(\mathrm{J} \mathrm{kg}^{-1} \mathrm{~K}^{-1}\right)$

$d$ - coefficient in the discretized equation (24) (-)

$D$ - mass transfer coefficient $\left(\mathrm{s}^{-1}\right)$

$H$ - heat transfer coefficient per unit of volume (W

$\mathrm{m}^{-3} \mathrm{~K}^{-1}$ )

$k$ - valve flow rating factor $\left(\mathrm{kg}^{1 / 2} \mathrm{~m}^{1 / 2}\right)$

$k_{c}$-coke combustion rate coefficient $\left(\mathrm{Pa}^{-1} \mathrm{~s}^{-1}\right)$

$k_{l j}, k_{2 j}, k_{3 j}, k_{4 j}$ - Coefficients for the fourth-order

Runge-Kutta method (-)

$k_{1}$ - combustion rate coefficient in reaction $\mathrm{i}\left(\mathrm{Pa}^{-1} \mathrm{~s}^{-1}\right)$

$k_{2}$ - combustion rate coefficient in reaction ii $\left(\mathrm{Pa}^{-1} \mathrm{~s}^{-1}\right)$

$k_{3 C}$-rate constant in reaction iii $\left(\mathrm{kmol} \mathrm{kg}^{-1} \mathrm{~s}^{-1} \mathrm{~Pa}^{-2}\right)$

$k_{4 h}$ - homogeneous rate constant in reaction iii $(\mathrm{kmol}$

$\left.\mathrm{m}^{-3} \mathrm{~s}^{-1} \mathrm{~Pa}^{-2}\right)$

$L-$ height (m)

$m-\operatorname{mass}(\mathrm{kg})$

$\dot{m}$ - mass flow rate $\left(\mathrm{kg} \mathrm{s}^{-1}\right)$

$M$ - molecular weight $\left(\mathrm{kg} \mathrm{kmol}^{-1}\right)$

$N$ - number of adjacent regions in equation (24) (-)

$P$ - pressure $(\mathrm{Pa})$

$\dot{Q}_{\text {los }}$ - rate of energy loss to the surroundings (kW)

$\dot{Q}_{\text {racc }}$ - rate of energy released by chemical reactions

$(\mathrm{kW})$

$r_{1}, r_{2}, r_{3}, r_{4}-$ reaction rates $\left(\mathrm{kmol} \mathrm{m}^{-3} \mathrm{~s}^{-1}\right)$
$R$ - ideal gas constant $\left(=8314.26 \mathrm{~J} \mathrm{kmol}^{-1} \mathrm{~K}^{-1}\right)$

$r^{\prime \prime \prime}$ - coke consumption rate per unit of volume

$\left(\mathrm{kmol} \mathrm{m}^{-3} \mathrm{~s}^{-1}\right)$

$R_{g}$ - rate of gas produced by combustion $\left(\mathrm{kg} \mathrm{s}^{-1}\right)$

$\mathrm{s}-$ coefficient in equation (24) (-)

$S$ - coefficient in equation (26) (-)

$s_{b}$ - coefficient in equation (24) (-)

$S_{b}-$ coefficient in equation (26) (-)

$t$ - time (s)

$T$ - temperature (K)

$V-$ volume $\left(\mathrm{m}^{3}\right)$

$v_{c}-$ catalyst velocity $\left(\mathrm{m} \mathrm{s}^{-1}\right)$

$v_{g}-$ gas velocity $\left(\mathrm{m} \mathrm{s}^{-1}\right)$

$U$ - overall heat transfer coefficient $\left(\mathrm{W} \mathrm{m}^{-2} \mathrm{~K}^{-1}\right)$

$w$ - coke on catalyst (-)

$\mathrm{x}-$ hydrogen to carbon atomic ratio in coke (-)

$X$ - valve stem position (-)

$y$ - mole fraction (-)

$z$ - vertical coordinate $(\mathrm{m})$

$Z$ - compressibility factor (-)

\section{Greek symbols}

$\alpha$ - valve head differential at maximum flow/valve head differential at zero flow [0 - 1] (-)

$\beta_{c}-\mathrm{CO} / \mathrm{CO}_{2}$ on the catalyst surface (-)

$\varepsilon$-volume fraction $[0-1](-)$

$\varepsilon_{m f}$ - void fraction in the dense bed at minimum

fluidizing condition (-) 
$\delta$ - volume fraction of the bubble phase

$\Delta H_{r}$ - heat of reaction (difference in the enthalpy of the products and reactants) $\left(\mathrm{kJ} \mathrm{m}^{-3} \mathrm{~s}^{-1}\right)$

$\Delta P$ - pressure difference across the valve $(\mathrm{Pa})$

$\Delta t$ - time step (s)

$\omega$ - coefficient in equation (26) (-)

$\psi$ - coefficient in equation (26) (-)

$\phi$ - a general variable $\left(m_{c, E}, m_{g, R}, w_{E}, C_{i, E}, T_{E}, C_{i, B}, T_{B}\right)$

in the discretized equation (24) (-)

$\rho$ - density $\left(\mathrm{kg} \mathrm{m}^{-3}\right)$

\section{Superscripts}

$a-$ feed air

$B$ - bubble phase

$c$ - catalyst

$C-$ cyclone

ck- coke

$\mathrm{CO}$ - carbon monoxide

$\mathrm{CO}_{2}-$ carbon dioxide

$D$ - dense bed

$E$ - emulsion phase

$F$ - freeboard

$g-$ gas

$i$ - different components: $\mathrm{O}_{2}, \mathrm{CO}, \mathrm{CO}_{2}, \mathrm{H}_{2} \mathrm{O}, \mathrm{N}_{2}$

$j$ - one of the ordinary differential equations in the

fourth-order Runge-Kutta method

$k$ - adjacent region defined in equation (24)

$\mathrm{N}_{2}$ - nitrogen

$\mathrm{O}_{2}$ - oxygen

$\mathrm{r}-$ regenerator

$R$ - regenerated

$S$ - spent

U - Upstream discrete point

$V$ - neighborhood

\section{Superscripts}

$\mathrm{t}$ - previous time

$\mathrm{t}+\Delta \mathrm{t}-$ current time

\section{INTRODUCTION}

Nowadays, hundreds of fluidized catalytic cracking (FCC) units are in operation worldwide, producing almost 500 million gallons of gasoline per day. This process is considered one of the most important developments in chemical engineering in the last century (NACS, 2003). Because of the large amount of gasoline produced, small efficiency gains can lead to significant increases in earnings, and as a result, major investments have been made to enhance the process's efficiency. The operational flexibility of the FCC process means that it can easily be adapted to the demands of local markets. Furthermore, the process is highly profitable, as heavy distillates with limited commercial value are converted into more expensive products. Residues from atmospheric and vacuum distillation (gasoil and other residues) are cracked into gasoline and LPG (Liquefied Petroleum
Gas) by the action of a catalyst (generally composed of silica and alumina) at high temperature. In addition, carbonic residues (coke) are deposited on the surface of the catalyst, reducing its activity. This endothermic process takes place in a vertical flow reactor (riser). Following this, the products are separated from the catalyst to prevent further cracking and avoid loss of performance. The spent catalyst then flows to a regenerator where the coke is burnt in a fluidized bed. The combustion reactivates the catalyst and provides energy for the cracking reactions.

From the modeling viewpoint, regeneration is very complex: it is a two-phase (solid - gas) flow combustion problem. Several studies have been carried out to model the regeneration process. For instance, McFarlane et al. (1993) developed a simulation model for the ESSO model IV FCC Unit. Lansarin (1997) proposed a mathematical model to simulate the steady-state behavior of a UOP Stacked converter. Ali and Rohani (1997) published a dynamic model of an FCC converter, which was later modified by Malay et al. (1999). Santos (2000) described different models for the regenerator. Han and Chung (2001a and 2001b) developed a dynamic FCC model in which the regenerator was divided into two regions.

Other authors published more specific studies of regenerator models. Errazu et al. (1979) developed a grid model for an FCCU regenerator. They concluded that the fluidized bed can usefully be represented by a CSTR without feed-gas bypass. De Lasa and Grace (1979) described a model for a fluidized-bed reactor with the dense bed treated as a CSTR. They assumed piston flow on the freeboard and concluded that modeling of the freeboard is very important. Lee et al. (1989) developed three different models for a typical regenerator and compared the results of these models with measurements from an industrial plant. Faltsi-Saravalou and Vasalos (1991) described a dynamic model of a two-region fluidized bed (dense and freeboard) and gave a rigorous description of the hydrodynamics of Geldart's A and B-type particles. They divided the dense bed into two phases: the bubble phase and emulsion phase. The freeboard above the dense region was modeled as a onedimensional flow reactor. Guigon and Large (1984) applied a two-phase flow model to a multistage regenerator. Filho et al. (1996) explored the influence of the air jet near the regenerator air distribution grid.

Based on these earlier works, a dynamic model for simulating the regeneration process in an FCC unit is presented. The model is based on the mass and energy conservation equations. The differential equations are solved by two numerical methods: the fourth-order Runge-Kutta method and the finitedifference method. The main aim of the present work is to investigate and compare the performance of these numerical methods. 


\section{MATHEMATICAL MODEL}

In the proposed model, the regenerator is divided into two distinct regions: the dense bed and the freeboard. The dense bed comprises two phases (the bubble and emulsion phases), as shown in Figure 1. The model is based on the following assumptions: i) heat and mass are exchanged between the bubble and emulsion phases; ii) most of the combustion takes place in the emulsion phase; iii) the regenerator exhaust gas consists of $\mathrm{CO}, \mathrm{CO}_{2}, \mathrm{O}_{2}, \mathrm{H}_{2} \mathrm{O}$ and $\mathrm{N}_{2}$; iv) the combustion of hydrogen is considered instantaneous; v) the hydrogen-carbon ratio is constant during the coke-burning process; vi) the cyclones are $100 \%$ efficient; vii) the specific heat of the catalyst is constant; viii) the specific heat of the gases is a function of the temperature; ix) the temperature is uniform throughout the dense bed and varies with height in the freeboard; and $\mathrm{x}$ ) solid and gas are in thermal equilibrium within the emulsion phase.

\section{Dense Bed}

In this study, the dense bed comprises: i) the emulsion phase, composed of gases and catalyst at minimum fluidization condition; and ii) the bubble phase, consisting of gas in excess of that needed for minimum fluidization. Both phases are considered as continuously stirred tank reactors (CSTRs)

\section{Emulsion Phase}

This phase is composed of solid particles (catalyst and coke), air $\left(\mathrm{O}_{2}\right.$ and $\left.\mathrm{N}_{2}\right)$ and combustion products $\left(\mathrm{CO}, \mathrm{CO}_{2}\right.$, and $\left.\mathrm{H}_{2} \mathrm{O}\right)$.

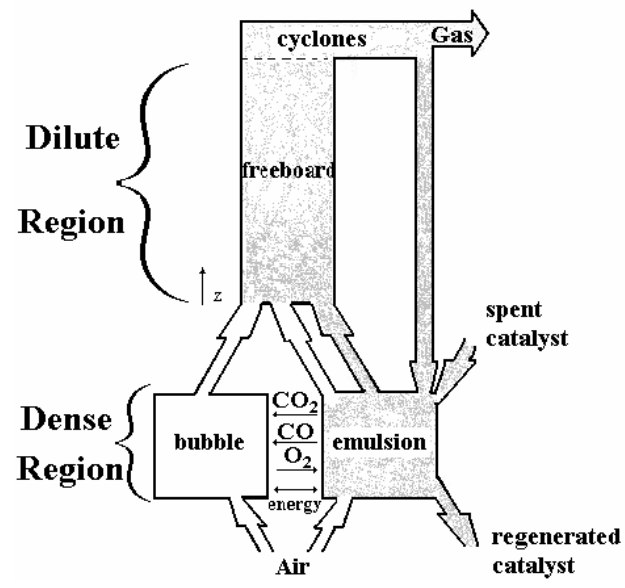

Figure 1 - The bubble and emulsion phase.

Mass conservation of solids: The rate of accumulation of catalyst within the emulsion phase is equal to the spent and recycled catalyst flow rates minus the regenerated catalyst flow rate and the catalyst flow rate to the freeboard: $\frac{d m_{c, E}}{d t}=\dot{m}_{c, S}+\dot{m}_{c, C}-\dot{m}_{c, R}-\dot{m}_{c, F}$

where $m$ is the mass and $\dot{m}$ the mass flow rate. The indices $c, S, C, R, E$ and $F$ represent catalyst, spent, cyclone, regenerated, emulsion and freeboard, respectively.

The coke mass balance within the emulsion phase, based on coke on catalyst, is given by the following equation:

$$
\begin{aligned}
& m_{c, E} \frac{d\left(w_{E}\right)}{d t}=\left(w_{S}-w_{E}\right) \dot{m}_{c, S}+\left(w_{C}-w_{E}\right) \dot{m}_{c, C} \\
& -r_{c k, E}^{\prime \prime \prime} M_{c k} V_{E}
\end{aligned}
$$

where $w$ is the coke on catalyst, $r{ }^{\prime \prime}$ the coke consumption rate per unit of volume, $M$ the molecular weight and $V$ the volume. The index $c k$ represents coke.

Mass conservation of gases: For a gas compound, the mass balance can be written as:

$$
\frac{d C_{i, E}}{d t}=\frac{v_{g, E}}{L_{D}}\left(C_{i, a}-C_{i, E}\right)+\frac{D_{B, E} \delta}{\varepsilon_{m f}(1-\delta)}\left(C_{i, B}-C_{i, E}\right)+\frac{r_{i, E}^{\prime \prime \prime}}{\varepsilon_{m f}}
$$

where $C$ is the molar concentration, $D$ the mass transfer coefficient, $L$ the height, $\varepsilon_{m f}$ the dense bed void fraction at the minimum fluidization condition, $\delta$ the volume fraction of the bubble phase and $v_{g}$ the gas velocity at minimum fluidization condition. The gas velocity and the void fraction at the minimum fluidization condition are calculated using Kunii and Levenspiel's (1996) model. The index $i$ represents the gas components $\mathrm{O}_{2}, \mathrm{CO}, \mathrm{CO}_{2}, \mathrm{H}_{2} \mathrm{O}$ and $\mathrm{N}_{2}$, and the indices $a, B$ and $D$, the feed air, bubble phase and dense bed, respectively.

Energy conservation: In the energy balance for the emulsion phase, the model assumes that the gas and catalyst are in thermal equilibrium:

$$
\begin{aligned}
& \left(m_{c, E} c_{p, c}+m_{g, E} c_{p, g, E}\right) \frac{d T_{E}}{d t}= \\
& \dot{m}_{c, S} c_{p, c}\left(T_{S}-T_{E}\right)+\dot{m}_{c, C} c_{p, c}\left(T_{C}-T_{E}\right)+\dot{m}_{a} c_{p g, E}\left(\frac{c_{p, a}}{c_{p, g, E}} T_{a}-T_{E}\right) \\
& +V_{B}\left[H_{B, E}+D_{B, E}\left(C_{O_{2}, B}-C_{O_{2}, E}\right) c_{p, O_{2}}\right]\left(T_{B}-T_{E}\right) \\
& +U_{V} A_{V}\left(T_{V}-T_{E}\right)-\sum \Delta H_{r, E} V_{E}
\end{aligned}
$$

where $T$ is the temperature, $c_{p}$ the specific heat, $U$ the overall heat transfer coefficient, $A$ the heat transfer area and $\Delta H_{r}$ the heat of the combustion reaction. $H$ is the heat transfer coefficient per unit of volume. The indices $g$ and $V$ are, respectively, gas and neighborhood. 


\section{Bubble Phase}

Mass conservation: The bubble phase comprises the mass of gas in excess of that needed for minimum fluidization. The oxidation of $\mathrm{CO}$ into $\mathrm{CO}_{2}$ is considered to take place within this phase. The rate of accumulation of component $i$ within this phase can be written as:

$$
\frac{d C_{i, B}}{d t}=\frac{v_{g, B}}{L_{E}}\left(C_{i, a}-C_{i, B}\right)+D_{B, E}\left(C_{i, E}-C_{i, B}\right)+r_{i, B}^{\prime \prime}
$$

where $v_{g, B}$ is the upward bubble velocity, which is a function of the superficial gas velocity and the average diameter of a single bubble in the bed (Levenspiel, 1998).

Energy conservation: In the energy balance for the bubble phase, the model assumes that all gas components within the bubble phase are in thermal equilibrium. The rate of energy accumulation accounts for the exchange of heat and mass with the emulsion phase, the energy transported by the inlet and outlet gas streams, and the heat generated by the combustion reactions:

$$
\begin{aligned}
& m_{g, B} c_{p, g, B} \frac{d T_{B}}{d t}=\left[H_{B, E} V_{B}+\sum D_{B, E} V_{B}\left(C_{i, E}-C_{i, B}\right) c_{p, i}\right]\left(T_{E}-T_{B}\right) \\
& +\dot{m}_{i, a, B} c_{p g, B}\left(\frac{c_{p, g, a}}{c_{p, g, B}} T_{a}-T_{B}\right)-\sum \Delta H_{r, B} V_{B}
\end{aligned}
$$

The outlet temperature of the dense bed is considered to be an average value of the emulsion and bubble phases weighted by the product of the respective specific heats and mass flow rates of these phases.

\section{Freeboard}

The freeboard is modeled as a one-dimensional flow reactor, and the temperature and concentration of each component therefore change with regenerator height as a result of combustion. The model predicts the coke combustion on the catalyst surface and also the oxidation of $\mathrm{CO}$ into $\mathrm{CO}_{2}$.

Mass conservation: The one-dimensional coke conservation equation can be written as:

$$
\frac{\partial\left(w_{F}\right)}{\partial t}+\frac{v_{c, F}}{\varepsilon_{c, F}} \frac{\partial\left(w_{F}\right)}{\partial z}=\frac{r_{c k, F}^{\prime \prime \prime} M_{c k}}{\varepsilon_{c, F} \rho_{c}}
$$

where $\varepsilon$ is the volume fraction and $v_{c}$ the catalyst velocity, which is based on the catalyst mass flow rate and is independent of the height. $\rho_{c}$ is the catalyst density.
The conservation of each gas species assumes the form:

$$
\frac{\partial\left(C_{i, F}\right)}{\partial t}+\frac{1}{\varepsilon_{g, F}} \frac{\partial\left(v_{g, F} C_{i, F}\right)}{\partial z}=\frac{r_{i, F}^{\prime \prime \prime}}{\varepsilon_{g, F}}
$$

where $v_{g, F}$ is the average gas velocity along the freeboard.

Energy conservation: The gas components are considered to be in thermal equilibrium with the catalyst. The conservation equation includes the advective transport, heat of reaction and heat loss through the regenerator walls:

$$
\begin{aligned}
& \left(\rho_{c} c_{p, c} \varepsilon_{c, F}+\rho_{g, F} c_{p, g, F} \varepsilon_{g, F}\right) \frac{\partial T_{F}}{\partial t}= \\
& -\left(v_{c, F} \rho_{c} c_{p, c}+v_{g, F} \rho_{g, F} c_{p, g, F}\right) \frac{\partial T_{F}}{\partial z}+\sum H_{i} r_{i, F}^{\prime \prime \prime}
\end{aligned}
$$

where $\sum H_{i} r_{i, F}^{\prime \prime \prime}$ is the rate of energy released by the combustion reactions. The catalyst fraction in the freeboard, $\varepsilon_{c, F}$, drops exponentially with height according to a correlation described by Kunii and Levenspiel (1996).

\section{Overall Mass Balance}

The overall mass of catalyst within the regenerator is the sum of the mass in the dense bed and freeboard:

$$
m_{c, r}=m_{c, E}+m_{c, F}
$$

The rate of change of the overall mass of gas stored in the regenerator is equal to the inlet air flow rate added to the coke combustion rate minus the exhausted gas flow rate:

$$
\frac{d m_{g, r}}{d t}=\dot{m}_{a}+R_{g, D}+R_{g, F}-\dot{m}_{g, C}
$$

where $R_{g}$ is the rate of gas produced by combustion within the dense bed, D, and freeboard, F.

\section{Pressure in the Regenerator}

The pressure within the regenerator is calculated according to the ideal gas law:

$$
P=\frac{\rho_{g, R} R T_{E}}{M_{g, R}} Z_{g}
$$

where $\mathrm{P}$ is the pressure, $Z$ the compressibility factor, $\mathrm{R}$ the ideal gas constant and $\rho_{\mathrm{g}, \mathrm{R}}$ the gas density computed as the ratio of the mass of gas to the volume of gas within the regenerator. 


\section{Control Valves}

The catalyst flow rate and gas flow rate throughout the transport lines are a function of the pressure differences across the valves:

$$
\dot{m}=\frac{k X}{\sqrt{\alpha+(1-\alpha) X^{2}}} \sqrt{\Delta P}
$$

where $k$ is the valve flow rate factor, $X$ the valve stem position, $\alpha$ the valve head differential at maximum flow/valve head differential at zero flow and $\Delta P$ the pressure difference across the valve.

\section{Combustion Kinetics Model}

Coke is usually composed of different chemical compounds $(\mathrm{C}, \mathrm{H}, \mathrm{N}, \mathrm{S})$ but consists mainly of carbon and hydrogen. In the present model, the following assumptions are made: coke consists of only $\mathrm{CH}_{\mathrm{x}}$ hydrocarbon, with a constant atomic ratio of hydrogen to carbon $(\mathrm{x}=0.9)$; the hydrogen reacts completely and instantaneously; and the combustion of coke is the slowest reaction (the bottleneck). The combustion of coke is divided into two reactions: one in which carbon monoxide is formed (Eq. (14)), and another, carbon dioxide (Eq. (15)). In addition to the burning of coke, oxidation of $\mathrm{CO}$ into $\mathrm{CO}_{2}$ (Eq. (16) and (17)) also takes place in the regenerator:

i) $\mathrm{CH}_{x}+(0.5+x / 4) \mathrm{O}_{2} \stackrel{k_{1}}{\rightarrow} \mathrm{CO}+x / 2 \mathrm{H}_{2} \mathrm{O}$

ii) $\mathrm{CH}_{x}+(1+x / 4) \mathrm{O}_{2} \stackrel{k_{2}}{\rightarrow} \mathrm{CO}_{2}+x / 2 \mathrm{H}_{2} \mathrm{O}$

iii) $\mathrm{CO}+1 / 2 \mathrm{O}_{2} \stackrel{k_{3 c}}{\rightarrow} \mathrm{CO}_{2}$

iv) $\mathrm{CO}+1 / 2 \mathrm{O}_{2} \stackrel{k_{4 h}}{\rightarrow} \mathrm{CO}_{2}$

where $\mathrm{x}$ is the hydrogen to carbon atomic ratio in coke, $k_{1}, k_{2}$ and $k_{3 c}$ the respective rate coefficients of the heterogeneous reactions, and $k_{4 h}$ the rate coefficient of the homogeneous reaction. The reaction rates for coke combustion are of second order and depend on the oxygen and coke concentrations:

$$
\begin{aligned}
& r_{1}=(1-\varepsilon) \rho_{c} k_{1} \frac{w}{M_{c k}} y_{O_{2}} P \\
& r_{2}=(1-\varepsilon) \rho_{c} k_{2} \frac{w}{M_{c k}} y_{O_{2}} P
\end{aligned}
$$

where $y$ is the mole fraction. The constants $k_{1}$ and $k_{2}$ are defined as:

$$
\begin{gathered}
k_{1}=\frac{\beta_{c} k_{c}}{\beta_{c}+1} \\
k_{2}=\frac{k_{c}}{\beta_{c}+1}
\end{gathered}
$$

where $k_{c}$ and $\beta_{c}$ are, respectively, the rate coefficient of the coke combustion reaction and the molar ratio of $\mathrm{CO}_{2}$ and $\mathrm{CO}$ on the catalyst surface (Arbel et. al., 1995). The oxidation of $\mathrm{CO}$ is dependent on the type of catalyst (composites of vanadium, nickel and copper contribute to the combustion) and can be homogeneous and/or heterogeneous. The reaction rates for the oxidation of $\mathrm{CO}$ (Eq. (16) and (17)) are given by:

$$
\begin{aligned}
& r_{3}=(1-\varepsilon) \rho_{c} k_{3 c} y_{O_{2}} y_{C O} P^{2} \\
& r_{4}=\varepsilon k_{4 h} y_{O_{2}} y_{C O} P^{2}
\end{aligned}
$$

All reaction constants $\left(\beta_{c}, k_{c}, k_{3 c}\right.$ and $\left.k_{4 h}\right)$ depend on the temperature and are calculated according to Arhenius' model (Fogler, 1999). The values of frequency factors and Activation Energy are reported in Table 1.

Table 1 - Energy of activation and frequency factors of the reaction constants $\beta_{\mathrm{c}}, \mathrm{k}_{\mathrm{c}}, \mathrm{k}_{3 \mathrm{c}}, \mathrm{k}_{4 \mathrm{~h}}$.

\begin{tabular}{|c|c|c|}
\hline Constant & $\begin{array}{c}\text { Energy of } \\
\text { Activation }\end{array}$ & Frequency Factor \\
\hline$\beta_{\mathrm{c}}$ & $\begin{array}{c}56501.8 \\
\mathrm{~kJ} / \mathrm{kmol}\end{array}$ & $\mathbf{2 5 1 2 ( - )}$ \\
\hline $\mathrm{k}_{\mathrm{c}}$ & $\begin{array}{c}158051.0 \\
\mathrm{~kJ} / \mathrm{kmol}\end{array}$ & $\mathbf{1 0 5 5}(\mathbf{P a . s})^{-1}$ \\
\hline $\mathrm{k}_{3 \mathrm{c}}$ & $\begin{array}{c}115479.4 \\
\mathrm{~kJ} / \mathrm{kmol}\end{array}$ & $\mathbf{6 1 5 . 6 5}\left(\mathbf{k m o l} / \mathbf{k g} / \mathbf{s} / \mathbf{P a}^{2}\right)$ \\
\hline $\mathbf{k}_{\mathbf{4 h}}$ & $\begin{array}{c}\mathbf{2 9 9 6 2 9 . 9} \\
\mathbf{k J} / \mathbf{k m o l}\end{array}$ & $\begin{array}{r}\mathbf{2 . 9 6 1 9 \times 1 0} \\
\left(\mathbf{k m o l} / \mathbf{m}^{\mathbf{3}} / \mathbf{s} / \mathbf{P a}^{\mathbf{2}}\right)\end{array}$ \\
\hline
\end{tabular}

\section{SOLUTION METHODS}

As the differential equations described above do not have a solution (because of their non-linearity), they are solved by numerical methods. Two approaches are employed: i) the finite-difference method (Patankar, 1980); and ii) the fourth-order Runge-Kutta method (Patankar, 1980). The fourthorder Runge-Kutta method is applied to initial-value problems, represented by ordinary differential equations, and the finite-difference method is employed for both ordinary and partial differential equations.

\section{Finite-Difference Method}

\section{Ordinary Differential Equations}


It can be seen that all the first order ordinary differential equations (1), (2), (3), (4), (5), (6) and (11) have the same form and can generally be written as,

$$
a \frac{d \phi}{d t}=\sum_{k=1}^{N} d_{k}\left(\phi_{k}-\phi\right)+s-s_{b}
$$

where $\phi$ represents one of the properties $m_{c, E}, m_{g, r g}, w_{c q, E}, C_{i, E}, T_{E}, C_{i, B}, T_{B} . \phi_{k}$ is the value of a property at an adjacent region (spent, cyclone, regenerated, emulsion, freeboard, feed air), $N$ indicates the number of interactions with adjacent regions, and the coefficients $a, d_{k}, s$ and $s_{b}$ are defined according to each conservation equation. Tables 2 and 3 show the coefficients for the mass and energy conservation equations, respectively.

Table 2 - Properties $\phi$ and $\phi_{k}$ and the coefficients $a_{a,}, s, s_{b}$ for the mass conservation equations.

\begin{tabular}{cccccc}
\hline & Equation (1) & Equation (2) & Equation (3) & Equation (5) & Equation (11) \\
\hline$\phi$ & $m_{c, E}$ & $w_{E}$ & $C_{i, E}$ & $C_{i, B}$ & $m_{g, r}$ \\
$\phi_{1}$ & - & $w_{S}$ & $C_{i, a}$ & $C_{i, a}$ & - \\
$\phi_{2}$ & - & $w_{C}$ & $C_{i, B}$ & $C_{i, E}$ & - \\
$a$ & 1 & $m_{c, E}$ & 1 & 1 & 1 \\
$d_{1}$ & - & $\dot{m}_{c, S}$ & $\frac{v_{g, E}}{L_{D}}$ & $\frac{v_{g, B}}{L_{E}}$ & - \\
$d_{2}$ & - & $\dot{m}_{c, C}$ & $\frac{D_{B, E} \delta}{\varepsilon_{m f}(1-\delta)}$ & $D_{B, E}$ & - \\
$s_{s}$ & $\dot{m}_{c, S}+\dot{m}_{c, C}$ & - & $\frac{r_{i, E}^{\prime \prime \prime}}{\varepsilon_{m f}}$ & $r_{i, B}^{\prime \prime \prime}$ & $\dot{m}_{a r}+R_{g, D}+R_{g, F}$ \\
$s_{b}$ & $\dot{m}_{c, R}+\dot{m}_{c, F}$ & $r_{c k, E}^{\prime \prime \prime} M_{c k} V_{E}$ & - & - & $\dot{m}_{g, C}$ \\
\hline
\end{tabular}

Table 3 - Properties $\phi$ and $\phi_{k}$ and the coefficients $a_{k}, d_{k}, s, s_{b}$ for the energy conservation equations.

\begin{tabular}{ccc}
\hline & Equation (4) & Equation (6) \\
\hline$\phi$ & $T_{E}$ & $T_{B}$ \\
$\phi_{1}$ & $T_{S}$ & - \\
$\phi_{2}$ & $T_{C}$ & - \\
$\phi_{3}$ & $c_{p, a}$ & $c_{p, a}$ \\
$c_{p, g, E}$ & $T_{p, g, B}$ \\
$\phi_{4}$ & $T_{B}$ & $T_{E}$ \\
$\phi_{5}$ & $T_{V}$ & - \\
$a$ & $m_{c, E} c_{p c}+m_{g, E} c_{p, g, E}$ & $m_{g, B} c_{p, g, B}$ \\
$d_{1}$ & $\dot{m}_{c, S} c_{p, c}$ & - \\
$d_{2}$ & $\dot{m}_{c, C} c_{p, c}$ & - \\
$d_{3}$ & $\dot{m}_{a} c_{p, g, E}$ & $\dot{m}_{i, a} c_{p, g, B}$ \\
$d_{4}$ & $H_{B, E} V_{B}+D_{B, E} V_{B}\left(C_{O_{2}, B}-C_{O_{2}, E}\right) c_{p, O_{2}}$ & $H_{B, E} V_{B}+D_{B, E} V_{B}\left(C_{i, E}-C_{i, B}\right) c_{p, i}$ \\
$d_{5}$ & $U_{V} A_{V}$ & - \\
$s$ & $-\sum \Delta H_{r, E} V_{E}$ & $-\sum \Delta H_{r, B} V_{B}$ \\
$s_{b}$ & - & - \\
\hline
\end{tabular}


The first order derivative of equation (24) can be approximated by the backward finite-difference approximation to yield the following expression:

$$
\begin{aligned}
& \left(\frac{a^{t+\Delta t}}{\Delta t}+\sum_{k=1}^{N} d_{k}^{t+\Delta t}\right) \phi^{t+\Delta t}=\sum_{k=1}^{N} d_{k}^{t+\Delta t} \phi_{k}^{t+\Delta t}+ \\
& \frac{a^{t+\Delta t}}{\Delta t} \phi^{t}+\left(s^{t+\Delta t}-s_{b}^{t+\Delta t}\right)
\end{aligned}
$$

where $\Delta \mathrm{t}$ is the time-step. The index $\mathrm{t}$ and $\mathrm{t}+\Delta \mathrm{t}$ represent past and present values.

\section{Partial Differential Equations}

The freeboard partial differential equations can be written in the general form:

$$
\omega_{j} \frac{\partial \phi_{j}}{\partial t}+\psi_{j} \frac{\partial \phi_{j}}{\partial z}=S_{j}-S_{b, j}
$$

where the coefficients $S_{j}, \psi_{j}, S_{j}$ and $S_{b, j}$ are defined according to one of the conservation equations and can be found in Table 4 .

Table 4 - Property $\phi_{j}$ and the coefficients $\omega_{j}, \psi_{j}, S_{j}$ and $S_{b, j}$.

\begin{tabular}{cccc}
\hline & Equation (7) & Equation (8) & Equation (9) \\
\hline$\phi$ & $w_{F}$ & $C_{i, F}$ & $T_{F}$ \\
$\omega_{j}$ & 1 & 1 & $\rho_{c} c_{p, c} \varepsilon_{c, F}+\rho_{g, F} c_{p, g, F} \varepsilon_{g, F}$ \\
$\psi_{j}$ & $\frac{v_{c, F}}{\varepsilon_{c, F}}$ & $\frac{v_{g, F}}{\varepsilon_{g, F}}$ & $v_{c, F} \rho_{c} c_{p c}+v_{g, F} \rho_{g, F} c_{p g, F}$ \\
$S_{j}$ & - & - & $\sum \Delta H_{i} r_{i, F}^{\prime \prime}$ \\
$S_{b, j}$ & $\frac{r_{c k, F}^{\prime \prime \prime} M_{c k}}{\varepsilon_{c, F} \rho_{c}}$ & $\frac{r_{i, F}^{\prime \prime \prime}}{\varepsilon_{g, F}}$ & - \\
\hline
\end{tabular}

Both time and spatial derivatives of equation (26) are discretized by backward approximations. This results in the following implicit finite-difference equation:

$$
\begin{aligned}
& \left(\omega_{j}^{t+\Delta t} \frac{\Delta y}{\Delta t}+\psi_{j}^{t+\Delta t}\right) \phi_{p}^{t}+\psi_{j}^{t+\Delta t} \phi_{s}^{t+\Delta t} \\
& +\left(s_{j}^{t+\Delta t}-s_{b, j}^{t+\Delta t}\right) \Delta y
\end{aligned}
$$

where the index $\mathrm{P}$ is the discretization point, $\mathrm{S}$ the nearest point to $\mathrm{P}$ in the upwind direction and $\Delta y$ the grid dimension, as shown in Figure 2. As can be seen, the property at point $\mathrm{P}$ can be evaluated as a function of the property at point S. In other words, evaluation of the discrete values starts at the nearest point to the dense-bed interface ( $\phi_{\mathrm{S}}$ is assumed to be the interface value) and evolves along the height.

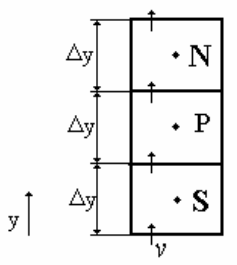

Figure 2 - One dimensional discretization.

Discretization provides two set of algebraic equations, represented by equation (25) for the dense bed and equation (27) for the freeboard.

\section{Convergence criterion}

The stability of a numerical method cannot usually be proven for non-linear sets of equations. The ability for the user to set up the grid is particularly important to obtain an accurate solution. Therefore, the convergence and numerical stability were checked by evaluating the solution's dependence on $\Delta t$ and $\Delta z$.

The implicit finite-difference method applied to linear equations is unconditionally stable and provides a solution for any value of $\Delta t$. The only restriction to the value of $\Delta t$ is the accuracy of the solution.

The convergence criterion adopted is the residues of the energy conservation equation:

$E_{s}=\max _{i=1 \ldots j}\left|R_{i}\right|<$ tol

$E_{s}$ is the maximum value between the dense and freeboard energy conservation equations. The iteration process stops when $E_{s}$ is smaller than a tolerance $(t o l)$. This criterion was adopted because the last equations to reach convergence were the energy equations.

\section{The Solution Algorithm}

The algebraic equations were solved sequentially, using an approach similar to the GaussSiedel method. Figure 3 shows the flowchart of the algorithm developed. Firstly, initial values are established for all the variables $\left(\phi_{1}^{0}, \phi_{2}^{0}, \ldots\right)$. Then the coefficients of the dense-bed equations and the respective $\phi$ values are calculated iteratively. Once the dense-bed equations have converged, the coefficients of the freeboard equations are computed. Finally, the $f$ values for the freeboard properties $\left(\phi_{1, z}^{k+1}, \phi_{2, z}^{k+1}, \ldots\right)$ are calculated. Convergence of the whole set of equations is checked. If convergence is not reached, the solution process restarts at the densebed equation. Finally, current values are attributed to 
previous ones and printed. A new time-step is then established and the simulation evolves until the last time-step is reached.

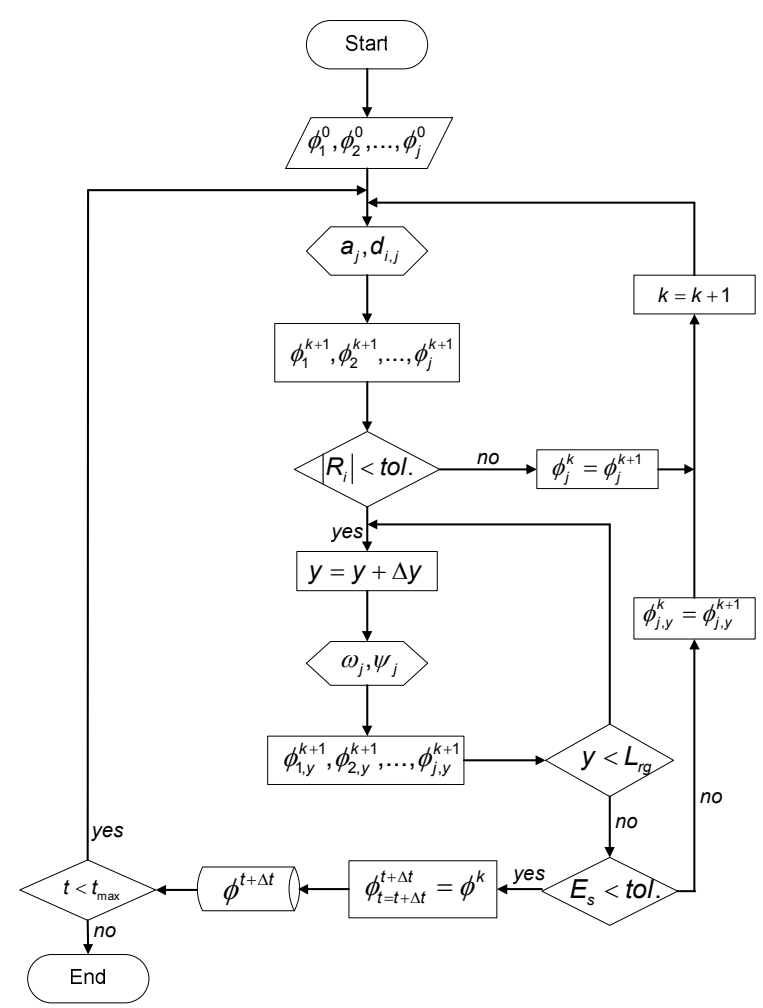

Figure 3 - Finite-Difference Algorithm.

\section{Fourth-Order Runge-Kutta Method}

\section{Ordinary Differential Equations}

According to the fourth-order Runge-Kutta method [20], the system of $j$ first order differential equations (Eqs. (1), (2), (3), (4), (5), (6) and (11)) can be written as,

$$
\begin{aligned}
& \frac{d \phi_{1}}{d t}=f_{1}\left(t, \phi_{1}, \phi_{2}, \ldots, \phi_{j}\right) \\
& \frac{d \phi_{2}}{d t}=f_{2}\left(t, \phi_{1}, \phi_{2}, \ldots, \phi_{j}\right) \\
& \vdots \\
& \frac{d \phi_{j}}{d t}=f_{j}\left(t, \phi_{1}, \phi_{2}, \ldots, \phi_{j}\right)
\end{aligned}
$$

and its general solution is

$$
\phi_{j}^{n+1}=\phi_{j}^{n}+\frac{1}{6}\left(k_{j 1}+2 k_{j 2}+2 k_{j 3}+k_{j 4}\right)
$$

where

$k_{j 1}=\Delta t f_{j}\left(t, \phi_{1}^{n}, \phi_{2}^{n}, \ldots, \phi_{j}^{n}\right)$,

$$
\begin{aligned}
& k_{j 2}=\Delta t f_{j}\left(t+\frac{1}{2} \Delta t, \phi_{1}^{n}+\frac{1}{2} k_{j 1}, \phi_{2}^{n}\right. \\
& \left.+\frac{1}{2} k_{j 1}, \ldots, \phi_{n}^{n}+\frac{1}{2} k_{j 1}\right) \\
& k_{j 3}=\Delta t f_{j}\left(t+\frac{1}{2} \Delta t, \phi_{1}^{n}+\frac{1}{2} k_{j 2}, \phi_{2}^{n}\right. \\
& \left.+\frac{1}{2} k_{j 2}, \ldots, \phi_{n}^{n}+\frac{1}{2} k_{j 2}\right) \\
& k_{j 4}=\Delta t f_{j}\left(t+\Delta t, \phi_{1}^{n}+k_{j 3}, \phi_{2}^{n}+k_{j 3}, \ldots, \phi_{n}^{n}+k_{j 3}\right)
\end{aligned}
$$

Note that the variables depend on the $\phi$ value at the previous time-step, indicating that the method is an explicit one. Iteration is therefore not required, and the equations can be solved sequentially.

\section{Partial Differential Equations}

As the freeboard partial differential equations (7), (8) and (9) cannot be solved directly by the fourth-order Runge-Kutta method, they are first discretized in the $\mathrm{z}$ direction, resulting in a set of ordinary differential equations (Eqs. (29)). These time-dependent equations are then solved by the fourth-order Runge-Kutta method.

To solve the freeboard equations, boundary conditions at the dense-bed interface are needed. The outputs of the dense-bed solution are the boundary conditions for the freeboard equations. Since the catalyst particles collected by the cyclones are recycled to the dense bed, there is interaction between the two sections, and their equations are therefore interdependent. To ensure the interdependence of the equations, the finitedifference solution is carried out iteratively between the dense-bed and the freeboard equations, as explained in Section 3.1.4.

As the fourth-order Runge-Kutta method is an explicit one, iterations are not necessary and the time solution is performed sequentially.

\section{RESULTS}

In this section the results of the proposed model are compared with experimental data and with the results of numerical models found in the literature ((Han, 2001a) and (Han, 2001b)).

\section{Verification of the Model}

This case study is based on the start-up of a PETROBRAS/SIX pilot plant located in São Mateus do Sul-PR, Brazil. At start-up, the regenerator temperature is assumed to be $900 \mathrm{~K}$, the pressure, 1.9 bar, and the coke on catalyst, zero. The molar concentrations of gas compounds $\left(\mathrm{CO}, \mathrm{CO}_{2}, \mathrm{H}_{2} \mathrm{O}, \mathrm{O}_{2}\right.$ and $\mathrm{N}_{2}$ ) are assumed to be identical to their concentrations in the feed air (see Table 5). For the 
purposes of the comparisons detailed in this section, the regenerator boundary conditions are assumed to be constant values, as shown in Table 5. The simulation was carried out over a 200 -minute period.

A comparison of the fourth-order Runge-Kutta and finite-difference methods is given below.

Table 5 - Regenerator boundary conditions.

\begin{tabular}{|l|c|c|}
\hline \multicolumn{1}{|c|}{ Variables } & Value & Unit \\
\hline Spent-catalyst mass flow rate & 0.13 & $\mathrm{Kg} / \mathrm{s}$ \\
\hline Spent-catalyst temperature & 790 & $\mathrm{~K}$ \\
\hline Coke on catalyst & 0.14 & $\mathrm{~kg}_{\text {coke }} / \mathrm{kg}_{\text {catal }}$ \\
\hline Feed-air mass flow rate & 0.05 & $\mathrm{Kg} / \mathrm{s}$ \\
\hline Air Temperature & 350 & $\mathrm{~K}$ \\
\hline $\begin{array}{l}\text { Molar concentration of } \mathrm{O}_{2} \text { in } \\
\text { the feed air }\end{array}$ & 0.20 & - \\
\hline $\begin{array}{l}\text { Molar concentration of } \mathrm{N}_{2} \text { in } \\
\text { the feed air }\end{array}$ & 0.79 & - \\
\hline $\begin{array}{l}\text { Molar concentration of } \mathrm{CO}_{2} \\
\text { in the feed air }\end{array}$ & 0.01 & - \\
\hline $\begin{array}{l}\text { Molar concentration of } \mathrm{CO}_{\text {in the feed air }} \\
\text { in concentration of } \mathrm{H}_{2} \mathrm{O}\end{array}$ & 0.00 & - \\
\hline $\begin{array}{l}\text { Molar con air } \\
\text { in the feed air }\end{array}$ & 0.00 & - \\
\hline
\end{tabular}

\section{Fourth-order Runge-Kutta method}

An analysis of the model's sensitivity to timestep size and the number of discrete nodes in the freeboard was carried out. As the fourth-order RungeKutta method is an explicit one, its stability depends on the time-step size. In the freeboard, the maximum time-step that provides a stable solution will also depend on the mesh size. For instance, only one volume is allowed in the dilute region, for a value of $\Delta \mathrm{t}=0.54 \mathrm{~s}$. As the number of points increases, the time-step must decrease to keep the ratio $\Delta z / \Delta t \geq 5.5$. This value is the ratio of the coefficients $\psi_{j}$ and $\omega_{j}$ in Equation (26), which is basically the ratio of the phase velocity (solid or gas) to the volume fraction (solid or void) of the phase in the freeboard. By discretizing Equation (26) in space and substituting it in the fourth-order Runge-Kutta Equation (30), it can be seen that the coefficient of $\phi_{P}^{n}$ can be negative if $\Delta z / \Delta t<\psi_{j} / \omega_{j}$; negative coefficients can cause instability in explicit methods (see Patankar, 1980).

Figure 4 shows the steady-state temperature along the regenerator height for different numbers of grid points. As the number of points increases from 10 to 20 , the temperature at each grid point increases by approximately $0.25 \mathrm{~K}$.

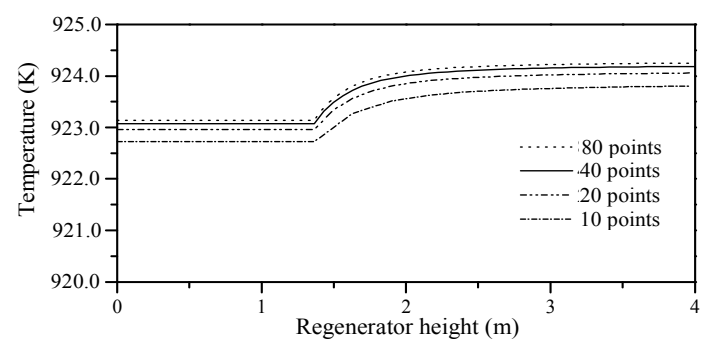

Figure 4 - Temperature profile for different meshes in the freeboard. Fourth-order Runge-Kutta solution.

As the catalyst mass flow leaving the freeboard returns by the cyclones to the dense bed, the number of grid points in the freeboard will affect this mass flow and, therefore, the dense-bed temperature. Table 6 shows the sensitivity of the temperature to the number of grid points. $\Delta \mathrm{T}$ is the maximum temperature difference between the result with a particular grid $(5,10,20,40$ or 80 -point) and the result with a 160 -point grid.

$\Delta \mathrm{t}$ in Table 6 corresponds to the maximum timestep that ensures the method is stable for the given number of grid points. The value that ensures the method is stable also provides a time-stepindependent solution. In other words, if the time-step is reduced, the same solution is obtained. Additionally, as the number of grid points doubles, the computational time more than triples. In view of the small difference between the 40 and 160-point grid results $(0.1 \mathrm{~K})$, the 40 -point grid is considered adequate.

\section{Finite-Difference Method}

First, an analysis of the convergence criterion (the sum of the residues of the energy equation - see Section 3.1.3) was carried out. Solutions for sums of residues of $1.0 \mathrm{~kW}, 0.1 \mathrm{~kW}$ and $0.001 \mathrm{~kW}$ were compared. The results were found to be insensitive to the sum of residues smaller than $0.001 \mathrm{~kW}$, and this value was therefore used henceforth as the convergence criterion.

Table 6 - Temperature change for different grids.

\begin{tabular}{|c|c|c|c|}
\hline $\begin{array}{c}\text { Grid } \\
\text { points }\end{array}$ & $\Delta \mathrm{t}(\mathrm{s})$ & $\Delta \mathrm{T}(\mathrm{K})$ & $\begin{array}{c}\text { Computational } \\
\text { time (min) }\end{array}$ \\
\hline 5 & 0.1 & 2.84 & $\mathbf{4}$ \\
\hline 10 & 0.049 & 0.4459 & $\mathbf{7 . 2}$ \\
\hline 20 & 0.023 & 0.2533 & $\mathbf{2 5 . 5}$ \\
\hline 40 & 0.0115 & 0.1186 & $\mathbf{7 8 . 2}$ \\
\hline 80 & 0.0060 & 0.0598 & $\mathbf{2 4 9 . 7}$ \\
\hline $\mathbf{1 6 0}$ & $\mathbf{0 . 0 0 2 5}$ & - & $\mathbf{1 3 3 3}$ \\
\hline
\end{tabular}

As already mentioned, there is no restriction in terms of time-step size in the implicit finitedifference method. Figure 5 shows the transient response of the spent-catalyst temperature for 
different time-steps. As expected, the steady-state is independent of the time-step. However, the smaller the time-step, the steeper the dynamic temperature gradient. Table 7 shows the maximum temperature difference between a certain time-step solution and a $7.5 \mathrm{~s}$ time-step result. As shown, 7.5s and 15s timestep results are quite close; therefore, a 15 s time-step solution is considered time-step independent.

Table 7 - Temperature difference for different timesteps.

\begin{tabular}{|c|c|}
\hline Time-step (s) & $\Delta \mathrm{T}_{\max }(\mathrm{K})$ \\
\hline 120 & 4.1 \\
\hline 60 & 2.3 \\
\hline 30 & 0.7 \\
\hline 15 & 0.05 \\
\hline
\end{tabular}

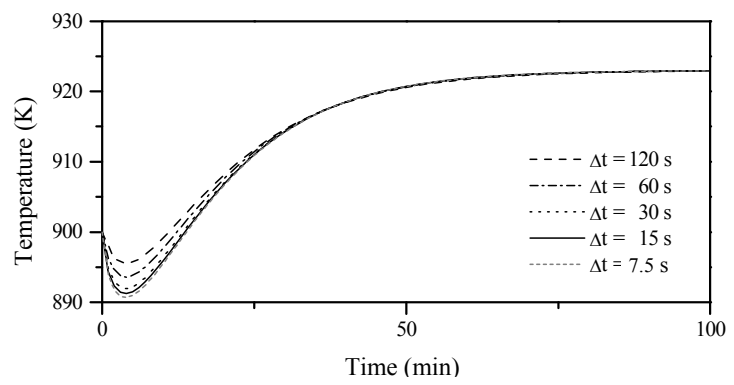

Figure 5 - Transient response of the spent-catalyst temperature for different time-steps and a 40-point mesh in the freeboard. Finite-difference solution.

Figure 6 shows the catalyst temperature in the emulsion phase for different grids and a $15 \mathrm{~s}$ timestep. The steady-state is sensitive to the number of grid points in the freeboard, showing the dependence of the dense bed on the freeboard solution. As with the fourth-order Runge-Kutta method, the 40-point grid provides a mesh-independent solution. Nevertheless, as the method is unconditionally stable, the number of grid points is not dependent on the time-step size. Therefore, a higher time-step can be used and a mesh-independent solution still be obtained, thereby considerably reducing the computational time.

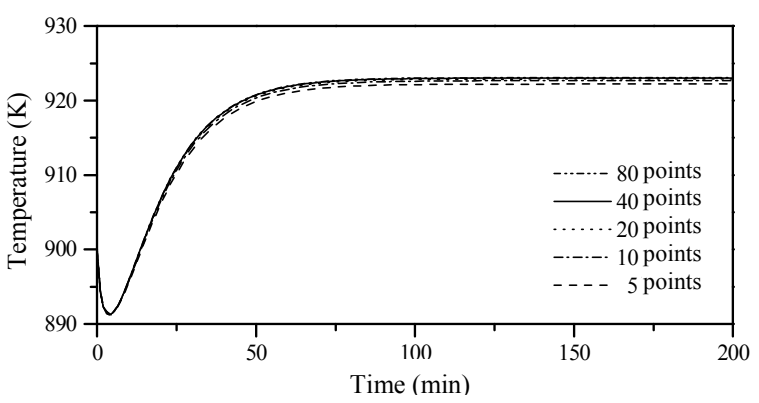

Figure $6-$ Transient response of dense-bed temperature for a $15 \mathrm{~s}$ time-step and different grids in the freeboard. Finite-difference solution.
The finite-difference and fourth-order RungeKutta methods give virtually the same results. For example, the maximum temperature difference is only $0.04 \mathrm{~K}$ for a $0.54 \mathrm{~s}$ time-step. Any value larger than this makes the solution unstable. Table 8 shows a comparison of the performance of the numerical methods. For a mesh-independent solution, the finite difference method is much faster. As the time-step is reduced, the finite-difference method becomes slower than the fourthorder Runge-Kutta approach; for $0.0115 \mathrm{~s}$, the computational time for the finitedifference method is 81 minutes, and for the RungeKutta method, 78 minutes.

Table 8 - Comparison of the finite-difference and fourth-order Runge-Kutta methods. Computer employed: Pentium III, 1.1GHz, 512MB.

\begin{tabular}{|l|c|c|}
\hline & $\begin{array}{c}\text { Fourth-order } \\
\text { Runge-Kutta }\end{array}$ & $\begin{array}{c}\text { Finite } \\
\text { Difference }\end{array}$ \\
\hline $\begin{array}{l}\text { Discretization } \\
\text { method }\end{array}$ & Explicit & Implicit \\
\hline Time step & $\begin{array}{c}\text { Conditionally } \\
\text { stable }\end{array}$ & $\begin{array}{c}\text { Unconditionally } \\
\text { stable }\end{array}$ \\
\hline $\begin{array}{l}\text { Convergence } \\
\text { Criterion }\end{array}$ & - & $\begin{array}{c}\text { Energy } \\
\text { equation } \\
\text { residue } \leq \mathbf{0 . 0 0 1} \\
\mathbf{k W}\end{array}$ \\
\hline $\begin{array}{l}\text { Grid dependence } \\
\text { interdependent }\end{array}$ & $\begin{array}{c}\Delta \mathbf{t} \text { e } \Delta \mathbf{z} \text { are } \\
\text { independent }\end{array}$ \\
\hline $\begin{array}{l}\text { Grid for mesh } \\
\text { independent } \\
\text { solution }\end{array}$ & 40 points & $\mathbf{4 0 ~ p o i n t s}$ \\
\hline $\begin{array}{l}\text { Computational } \\
\text { time for a } \\
\Delta t=0.01115 \mathrm{~s}\end{array}$ & 78.2 min & $\mathbf{8 1 ~ m i n}$ \\
\hline $\begin{array}{l}\text { Computational } \\
\text { time for a } \\
\text { time-step } \\
\text { independent } \\
\text { solutions }\end{array}$ & $\mathbf{7 8 . 2 ~ m i n}$ & $\mathbf{1 ~ m i n}$ \\
\hline
\end{tabular}

\section{Experimental Comparison}

Comparison of the results of the proposed model with the steady-state experimental values from the PETROBRÁS/SIX ${ }^{\#}$ pilot FCCU plant revealed that the computed regenerated-catalyst temperature and coke on catalyst are smaller and larger, respectively, than their experimental counterparts. The small amount of gas exchanged between the emulsion and bubble phases is a possible cause of these discrepancies. Falsti-Saravalou and Vasalos (1991) explained that this mass exchange is strongly dependent on the bubble sizes within the dense bed. It is probable, therefore, that the correlation used to

\footnotetext{
\# A business unit of Petrobrás S/A, located in São Mateus do Sul-PR, Brazil.
} 
estimate the bubble diameters gave inappropriate values. Table 9 shows a comparison of plant data with computed values for different bubble diameters.

Table 9 - Comparison of the results obtained with the proposed model and experimental data for different bubble diameters.

\begin{tabular}{|c|c|c|c|c|c|}
\hline Variable & \multirow{2}{*}{ Plant } & \multicolumn{3}{|c|}{ Bubble diameter $(\mathrm{m})$} & \multirow{2}{*}{ Unit } \\
\cline { 3 - 5 } & & 0.15 & 0.1 & 0.04 & \\
\hline $\mathrm{T}_{\mathrm{E}}$ & 995.1 & 944.6 & 978.3 & 957.2 & $\mathbf{K}$ \\
\hline $\mathrm{T}_{\mathrm{F}}$ & 947.2 & 960.2 & 938.4 & 934.2 & $\mathbf{K}$ \\
\hline $\mathrm{W}_{\mathrm{E}}$ & 0.048 & 0.24 & 0.031 & 0.026 & $\mathbf{\%}$ \\
\hline $\mathrm{C}_{\mathrm{CO}}$ & 0.00 & 0.00 & 0.06 & 0.40 & $\mathbf{\%}$ \\
\hline $\mathrm{C}_{\mathrm{CO} 2}$ & 8.31 & 7.36 & 8.65 & 8.42 & $\mathbf{\%}$ \\
\hline $\mathrm{C}_{\mathrm{O} 2}$ & 11.17 & 12.34 & 10.75 & 10.82 & $\mathbf{\%}$ \\
\hline $\mathbf{C}_{\mathbf{N} \mathbf{2}}$ & $\mathbf{7 9 . 5 7}$ & $\mathbf{8 0 . 3 0}$ & $\mathbf{8 0 . 5 4}$ & $\mathbf{8 0 . 3 6}$ & $\mathbf{\%}$ \\
\hline
\end{tabular}

A bubble diameter of $0.1 \mathrm{~m}$ yields the closest results to the experimental data. The bubble size that provides the best results is approximately half that obtained by the empirical correlation. A bubble diameter less than $0.035 \mathrm{~m}$ makes the solution unstable and is the lowest limit at which the correlation is still valid. For a bubble diameter of $0.1 \mathrm{~m}$, the bubble velocity and void fraction, which also depend on the bubble diameter, agree with values given by Santos [6].

Two models of combustion kinetics were tested: the model proposed by Arbel et al. [17] and that described by Han and Chung (2001a) and (2001b). As shown in Table 10, the results obtained using the model proposed by Arbel et al. [17] are closer to the experimental data than the results obtained with the model described by Han and Chung for most variables.

Table 10 - Comparison of two kinetic models found in the literature.

\begin{tabular}{|c|c|c|c|c|}
\hline Variable & Plant & $\begin{array}{c}\text { Arbel } \\
\text { et al. } \\
(1995)\end{array}$ & $\begin{array}{c}\text { Han and } \\
\text { Chung } \\
(2001 \mathrm{a} \mathrm{e} \mathrm{b})\end{array}$ & Unit \\
\hline $\mathrm{T}_{\mathrm{E}}$ & 995.1 & 978.3 & 958.5 & $\mathbf{K}$ \\
\hline $\mathrm{T}_{\mathrm{F}}$ & 947.2 & 938.4 & 906.1 & $\mathbf{K}$ \\
\hline $\mathrm{W}_{\mathrm{E}}$ & 0.048 & 0.031 & 0.065 & $\mathbf{\%}$ \\
\hline $\mathrm{C}_{\mathrm{CO}}$ & 0.00 & 0.06 & 0.54 & $\mathbf{\%}$ \\
\hline $\mathrm{C}_{\mathrm{CO} 2}$ & 8.31 & 8.65 & 7.91 & $\mathbf{\%}$ \\
\hline $\mathrm{C}_{\mathrm{O} 2}$ & 11.17 & 10.75 & 11.27 & $\mathbf{\%}$ \\
\hline $\mathbf{C}_{\mathbf{N} 2}$ & $\mathbf{7 9 . 5 7}$ & $\mathbf{8 0 . 5 4}$ & $\mathbf{8 0 . 2 8}$ & $\mathbf{\%}$ \\
\hline
\end{tabular}

Therefore, the kinetic model described by Arbel et al. is used for the other comparisons, including that in Table 9. In order to check the influence of the freeboard on the regenerator model, a second approach was considered, in which the freeboard was excluded (i.e., a one-bed model). A comparison of the complete model with the one-bed approach is shown in Table 11. The coke on regenerated catalyst and the outlet molar concentrations of $\mathrm{CO}$ and $\mathrm{CO}_{2}$ obtained with the complete model are closer to the experimental data. On the other hand, the temperature of the regenerated catalyst provided by the one-bed model is nearer to that of its experimental counterpart. This comparison clearly demonstrates the influence of the freeboard on the combustion of $\mathrm{CO}$. When the model including the freeboard is used, the values for the outlet molar concentrations and coke on catalyst approximate to the experimental values.

Table 11 - Comparison of the two-bed (dense and freeboard) and one-bed models.

\begin{tabular}{|c|c|c|c|c|}
\hline & Two-bed & Plant & One-bed & Unit \\
\hline $\mathrm{T}_{\mathrm{E}}$ & 978.3 & 995.1 & 1006.0 & $\mathbf{K}$ \\
\hline $\mathrm{T}_{\mathrm{F}}$ & 938.4 & 947.2 & - & $\mathbf{K}$ \\
\hline $\mathrm{W}_{\mathrm{E}}$ & 0.031 & 0.048 & 0.023 & $\mathbf{\%}$ \\
\hline $\mathrm{C}_{\mathrm{CO}}$ & 0.06 & 0.000 & 0.93 & $\mathbf{\%}$ \\
\hline $\mathrm{C}_{\mathrm{CO} 2}$ & 8.65 & 8.31 & 7.75 & $\mathbf{\%}$ \\
\hline $\mathrm{C}_{\mathrm{O} 2}$ & 10.75 & 11.17 & 11.15 & $\mathbf{\%}$ \\
\hline $\mathbf{C}_{\mathbf{N} 2}$ & $\mathbf{8 0 . 5 4}$ & $\mathbf{7 9 . 5 7}$ & $\mathbf{8 0 . 1 7}$ & $\mathbf{\%}$ \\
\hline
\end{tabular}

In the conditions prevailing in the case study, the plant operates with excess oxygen, so that most reactions are complete and take place in the dense bed. It is for this reason that results for the one-bed model and those for the complete model are similar. When there is no excess $\mathrm{O}_{2}$, a significant amount of $\mathrm{CO}$ is oxidized in the freeboard, in which case the complete model is more appropriate.

\section{Numerical Comparison}

Following is a comparison of the proposed model with that proposed by Han and Chung ((2001a) and (2001b)).

Han and Chung (2001b) modeled the whole FCC, including the riser, regenerator, reactor and valves. In order to compare the two models, the values of some variables (the inlet-air and spentcatalyst flow rates (see Figure 7), coke on spent catalyst and spent-catalyst temperature (see Figure 8)) obtained from Han and Chung's (2001b) results were established as the boundary conditions of the proposed model. After 10 minutes of simulation, the airflow rate was increased from $34 \mathrm{~kg} / \mathrm{s}$ to $35.7 \mathrm{~kg} / \mathrm{s}$. This value was kept unchanged until the simulation had continued for 150 minutes, when the flow rate was reduced to its initial value. The air temperature was maintained constant at $432 \mathrm{~K}$ throughout the simulation. 


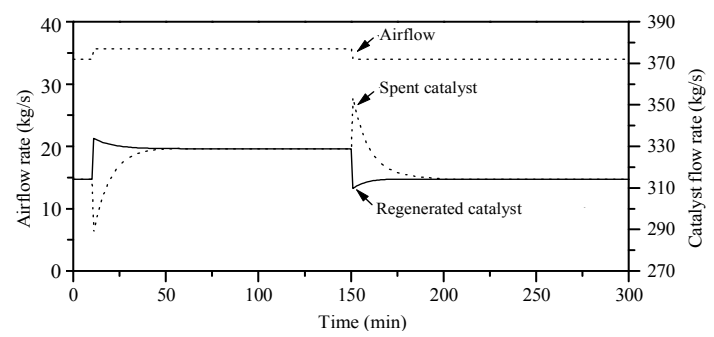

Figure 7 - Air, regenerated-catalyst and spentcatalyst flow rates (Han and Chung (2001b)) transient boundary conditions.

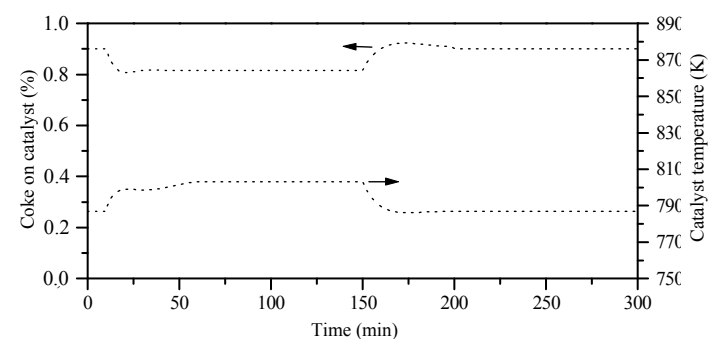

Figure 8 - Coke on spent catalyst and spent-catalyst temperature (Han and Chung (2001b)) - transient boundary conditions.

Beyond the boundary conditions, the proposed approach also uses the Han and Chung (2001b) models for combustion kinetics, mass transfer coefficient and control valves. It should be noted that Han and Chung's model assumes there are onedimensional variations of gas properties within the whole regenerator, whereas the proposed model only assumes this within the freeboard. These are the differences between the models.

\section{Steady-state comparison}

Initially, a steady-state comparison of the proposed model and Han and Chung's (2001b) model was conducted. The fixed boundary conditions are shown in Table 12, and the comparison of the main variables is given in Table 13 .

Table 12 - Boundary conditions for the steady-state comparison between the proposed model and Han and Chung's (2001b) model.

\begin{tabular}{|l|c|c|}
\hline \multicolumn{1}{|c|}{ Variable } & Value & Unit \\
\hline Spent catalyst flow rate & 314 & $\mathbf{~ k g} / \mathbf{s}$ \\
\hline Spent catalyst temperature & 787 & $\mathbf{K}$ \\
\hline Coke on spent catalyst & 0.9 & $\mathbf{\%}$ \\
\hline Air flow rate & 34 & $\mathbf{~ k g} / \mathbf{s}$ \\
\hline Inlet air temperature & $\mathbf{4 3 2}$ & $\mathbf{K}$ \\
\hline
\end{tabular}

Table 13 - Steady-state comparison of the proposed model and Han and Chung's (2001b) model.

\begin{tabular}{|l|c|c|c|}
\hline Variable & $\begin{array}{c}\text { Han and } \\
\text { Chung } \\
(2001 \mathrm{~b})\end{array}$ & $\begin{array}{c}\text { Current } \\
\text { model }\end{array}$ & Unit \\
\hline $\begin{array}{l}\text { Coke on the regen. } \\
\text { catalyst }\end{array}$ & 0.1 & 0.13 & $\%$ \\
\hline $\begin{array}{l}\text { Regen.-Catalyst } \\
\text { temperature }\end{array}$ & 991.0 & 1003.4 & $\mathrm{~K}$ \\
\hline Molar concentr. of $\mathrm{CO}_{2}$ & 14.80 & 14.86 & $\%$ \\
\hline Molar concentr. of $\mathrm{CO}$ & 0.4 & 2.31 & $\%$ \\
\hline Molar concentr. of $\mathrm{O}_{2}$ & 0.2 & 0.06 & $\%$ \\
\hline Molar concentr. of $\mathrm{H}_{2} \mathrm{O}$ & 9.20 & 7.72 & $\%$ \\
\hline
\end{tabular}

The molar concentrations of $\mathrm{CO}_{2}$ and the temperatures obtained with both models are in good agreement. The values for the coke on regenerated catalyst obtained with both models are small: $0.10 \%$ and $0.13 \%$ for the present model and the Han and Chung model, respectively. However, the molar concentrations of $\mathrm{CO}, \mathrm{O}_{2}$ and $\mathrm{H}_{2} \mathrm{O}$ for the proposed model differ slightly from those obtained by Han and Chung. These differences can be attributed to the modeling of the dense bed, as Han and Chung (2001b) employed a distributed model and the approach described here assumes it is uniform.

\section{Dynamic Comparison}

As shown in Figure 9, the transient response of the coke on regenerated catalyst and regeneratedcatalyst temperature obtained with the proposed model and those obtained with Han and Chung's model ((2001a) and (2001b)) are similar. Because of the low molar concentration, the discrepancies between the two models appear quite large (see Figure 10). However, the maximum molar concentration is in the order of $2.5 \%$ and the differences in concentration are under $2 \%$. Despite these differences, the models show similar trends.

\section{Sensitivity Analysis}

Lastly, an analysis of the sensitivity of the proposed model to all the boundary conditions was carried out for the operating conditions and geometry described in Section 4.1 (The PETROBRAS/SIX pilot FCCU plant). 


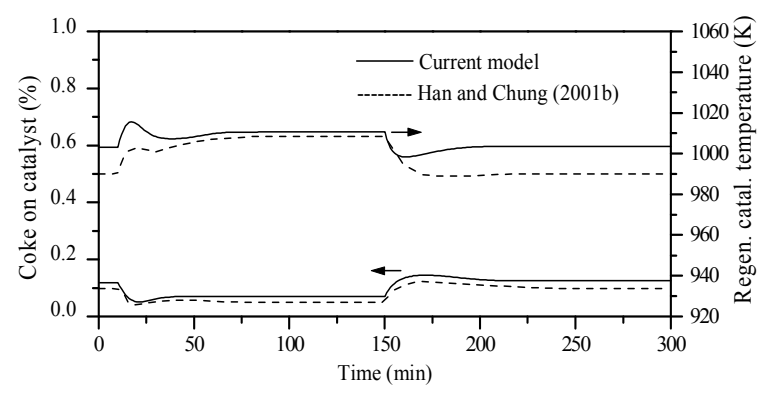

Figure 9 - Numerical comparison of coke on regenerated catalyst and regenerated-catalyst temperature.

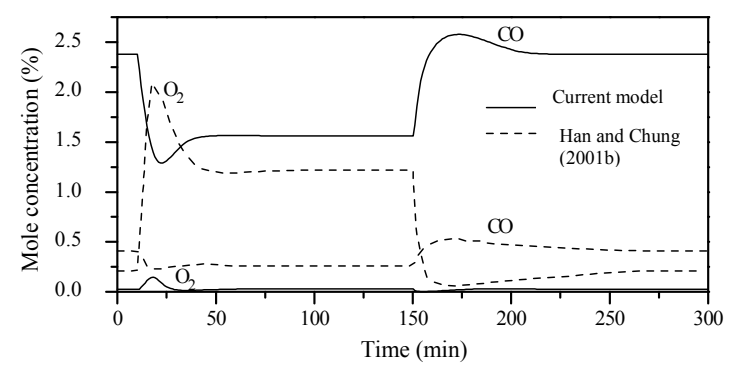

Figure 10 - Numerical comparison of $\mathrm{CO}$ and $\mathrm{CO}_{2}$ molar concentrations at the regenerator outlet.

As the boundary conditions were changed one by one, the transient behavior of the regenerator temperature, coke on regenerated catalyst and gas composition was similar to a first-order system response. The time for all variables to stabilize was less than 25 minutes. This is of the same order as the ratio of the mass of catalyst within the regenerator to the mass flow rate of the spent catalyst. As the transient responses of all the variables are quite similar, they are not shown. The sensitivity analysis was thus performed only for steady-state conditions.

\section{Effect of the spent-catalyst flow rate}

Figure 11 shows the steady regenerated-catalyst temperature and coke on regenerated catalyst as a function of the spent-catalyst flow rate. The maximum temperature can be seen to occur at a flow rate of $250 \mathrm{~kg} / \mathrm{s}$. For flow rates higher than $250 \mathrm{~kg} / \mathrm{s}$ there is insufficient oxygen to burn the coke, and for lower flow rates there is excess oxygen.

This is characteristic of the transition from partial to total combustion, which can be achieved by either increasing the coke on spent catalyst or its flow rate. Both procedures raise the amount of coke in the regenerator. The higher the catalyst flow rate the lower the oxygen/coke ratio and, consequently, the lower the combustion rate.

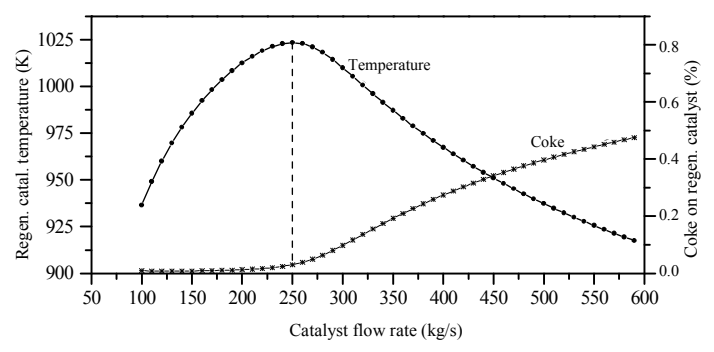

Figure 11 - Regenerated-catalyst temperature and coke on regenerated catalyst in steady state as a function of the spent-catalyst flow rate.

\section{Effect of the coke on spent catalyst}

Up to a limit of $1.0 \%$, the higher the coke on spent catalyst the higher the regenerator temperature. Above that limit, the temperature stabilizes at a constant value (see Figure 12) because of the lack of oxygen to burn the coke that is fed in. As a result, the coke on regenerated catalyst starts to increase.

\section{Effect of the spent-catalyst temperature}

Figure 13 shows the regenerated-catalyst temperature and coke on regenerated catalyst as a function of the spent-catalyst temperature. It can be seen that both curves are discontinuous, with two steady states for the spent-catalyst temperature between 632 and $667 \mathrm{~K}$.

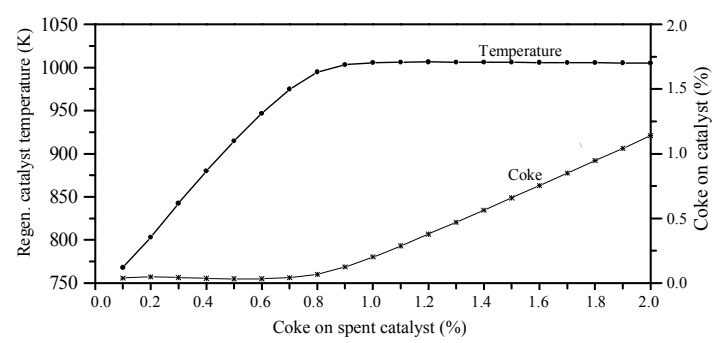

Figure 12 - Regenerated-catalyst temperature and coke on regenerated catalyst in steady state as a function of coke on spent catalyst.

The lower temperature curve is obtained by a progressive increase in the spent-catalyst temperature. When the spent-catalyst temperature reaches $667 \mathrm{~K}$, a small increase in this temperature produces a step change in the operating conditions the regenerated-catalyst temperature jumps from 678.3 to $873.3 \mathrm{~K}$. According to Fogler [18], the low spent-catalyst temperature, where the discontinuity takes place, is called the ignition temperature. 


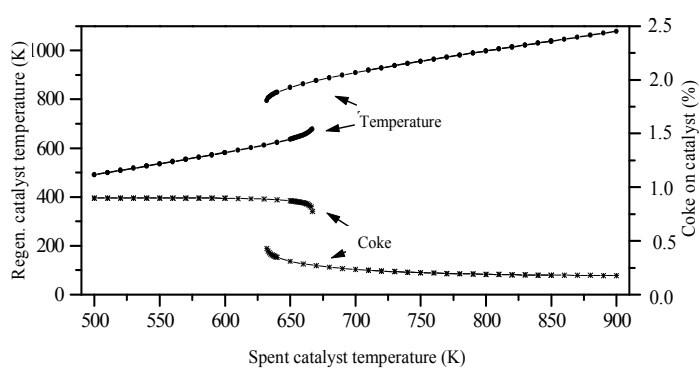

Figure 13 - Regenerated-catalyst temperature and coke on regenerated catalyst in steady state as a function of spent-catalyst temperature.

Figure 14 shows the molar concentration of oxygen at the regenerator outlet as a function of the spent-catalyst temperature. When the oxygen molar concentration is low (spent-catalyst temperature higher than $800 \mathrm{~K}$ ), an increase in the spent-catalyst temperature does not improve the combustion rate. Therefore, the regenerated-catalyst temperature only rises because of the higher energy of the spentcatalyst itself. A discontinuity can also be observed when the spent-catalyst temperature is reduced. At $632 \mathrm{~K}$, the steady state of the system jumps to a lower value. This value is called the extinction point (Han and Chung 2001b). As can be seen, there is hysteresis between the ignition and extinction points. The spentcatalyst temperature between these two values can lead to one or other steady state. Operation near this region is not desirable, as any disturbance can lead to instability.

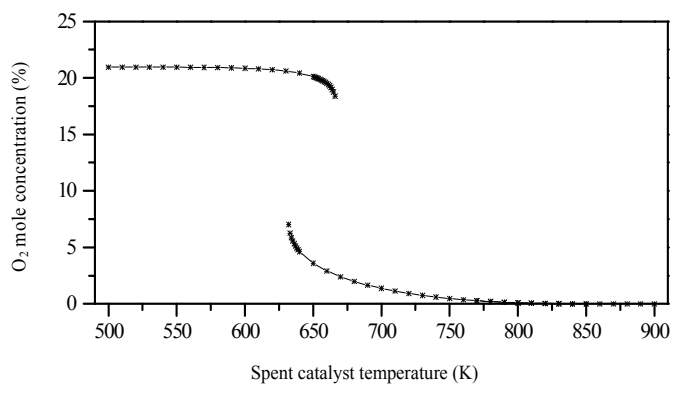

Figure 14 - Molar concentration of oxygen in steady state as a function of spent-catalyst temperature.

\section{Effect of the air flow rate}

The outlet composition of the gases as a function of the inlet air flow rate is shown in Figure 15. The higher the inlet air flow rate, the lower the concentration of CO. As the amount of available $\mathrm{O}_{2}$ increases, less $\mathrm{CO}$ is formed, and combustion changes from partial to complete. This change in combustion regime is confirmed by Figure 16, which shows the reduction in coke on catalyst and increase in regenerated catalyst temperature as the air flow rate increases.

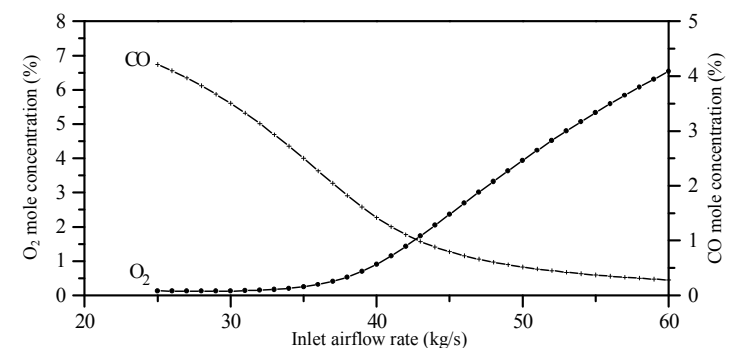

Figure $15-$ Molar concentrations of carbon monoxide and oxygen at the regenerator outlet in steady state as a function of inlet air flow rate.

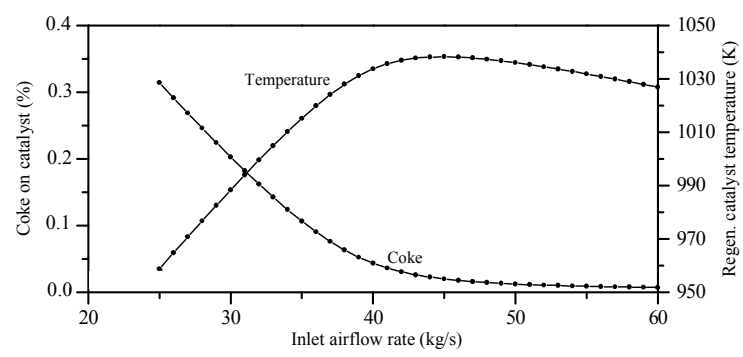

Figure 16 - Regenerated-catalyst temperature and coke on regenerated catalyst in steady state as a function of the inlet air flow rate.

A maximum temperature is observed at an air flow rate of $44 \mathrm{~kg} / \mathrm{s}$. Above this maximum temperature, the coke on catalyst becomes very low. High temperatures and excess oxygen are characteristics of complete combustion. The regenerator therefore works at complete combustion for air flow rates greater than $44 \mathrm{~kg} / \mathrm{s}$, when the temperature is less sensitive to the inlet air flow rate. The excess oxygen helps to reduce the regenerator temperature once the air is cold, while the excess air significantly improves the combustion process.

\section{Effect of inlet air temperature}

A $10 \mathrm{~K}$ increase in inlet air temperature produces a $1 \mathrm{~K}$ increase in regenerated-catalyst temperature. This relationship is almost linear irrespective of the inlet temperature, as the energy carried by the air is small compared with that produced by combustion.

\section{CONCLUSIONS}

This paper describes a dynamic model for an FCCU regenerator based on both the equations for the conservation of energy and mass and empirical correlations. The regenerator is composed of two beds: the dense bed and freeboard. The dense bed comprises bubble and emulsion phases. Both phases are considered to be CSTRs (Continuously Stirred Tank Reactors). The freeboard model is considered one-dimensional, as its properties vary with regenerator height. The conservation equations for 
the dense bed and freeboard are ordinary and partial differential equations, respectively. Two approaches are used to solve these equations: the fourth-order Runge-Kutta method and the implicit finitedifference method. To solve the partial differential equations by the fourth-order Runge-Kutta method, the space derivative is discretized using the finitedifference approach and a set of ordinary differential equations that can be solved by the fourth-order Runge-Kutta method is obtained.

Comparison of the solution methods revealed that the fourth-order Runge-Kutta method is slightly faster than the finite-difference method when the same time-step is used. To avoid instabilities, however, a very small time-step is needed for the fourth-order Runge-Kutta method. In contrast, there is no restriction on the size of the time-step in the implicit finite-difference method. Larger time-steps can therefore be used, so that the finite-difference method becomes much faster than the fourth-order Runge-Kutta approach.

A simulation was carried out with and without the freeboard to investigate the effect of this region. The combustion of coke and oxidation of $\mathrm{CO}$ that takes place in the freeboard not only changes the composition and temperature of the outlet gases but also the coke on catalyst that returns from the cyclones to the dense region.

The steady-state results for the model were corroborated by experimental data and found to be very sensitive to the diameter of the bubbles in the dense bed. Arbel et al's [17] kinetic model showed better agreement with the experimental data than Han and Chung's model ((2001a) and (2001b)). The model proposed in this paper was also compared with Han and Chung's dynamic FCCU model ((2001a) and (2001b)) and was found to be in reasonable agreement with it.

Finally, an analysis of the model's sensitivity to the regenerator boundary conditions was performed. In general, regenerator performance depends on the reactants that are available for combustion. The influence of a certain variable is therefore dependent on whether the combustion regime is partial or complete.

\section{ACKNOWLEDGMENTS}

The authors wish to express their gratitude for the financial support provided by

i) the Brazilian National Oil Agency (ANP) and FINEP through the ANP Human Resources Program for the Oil and Gas Sector (PRH-10/UTFPR-PR);

ii) FINEP/PETROBRAS (the OCUCC project); and iii) the CAPES Foundation.

The authors would also like to thank PETROBRAS/SIX for the experimental data provided for the steady-state comparison.

\section{REFERENCES}

Ali, H. and Rohani, S., 1997, Dynamic Modeling and Simulation of a Riser-Type Fluid Catalytic Cracking Unit. Chemical Engineering Technology, Vol. 20, pp. 118-130.

Arbel, A., Huang, Z., Rinard, I. H., Shinnai, R. and Sapre, A. V., 1995, Dynamic and Control of Fluidized Catalytic Crackers. 1. Modeling of the Current Generation of FCC's. Industrial and Engineering Chemistry Research, Vol. 34, No. 4, pp. 1228-1243.

Carnahan, B., 1990, Applied Numerical Methods, Melbourne: Krieger Publishing Company.

De Lasa, H. I. and Grace, J. R., 1979, The Influence of the Freeboard Region in a Fluidized Bed Catalytic Cracking Regenerator, AIChE Journal, Vol. 25, No. 6, pp. 984-991.

Errazu, A. F., De Lasa, H. I. and Sarti, F., 1979, A Fluidized Bed Catalytic Regenerator Model - Grid Effects. The Canadian Journal of Chemical Engineering, Vol. 57, pp. 191-197.

Faltsi-Saravelou, O. and Vasalos, I. A., 1991, FBSim: a Model for Fluidized Bed Simulation - I. Dynamic Modeling of an Adiabatic Reacting System of Small Gas Fluidized Particles. Computers and Chemical Engineering, Vol. 15, No. 9, pp. 639-646.

Filho, R. M., Batista, M. F. L. and Fusco, M., 1996, A Fast Fluidized Bed Reactor for Industrial FCC Regenerator. Chemical Engineering Science, Vol. 51, No. 10, pp. 1807-1816.

Fogler, H. S., 1999, Elements of Chemical Reaction Engineering. 3rd edition. New Jersey: Prentice-Hall Inc.

Guigon, P. and Large, J. F., 1984, Application of the Kunni-Levenspiel Model to a Multistage Baffled Catalytic Cracking Regenerator. The Chemical Engineering Journal, Vol. 28, No. 3, pp. 131-138.

Han, I. S. and Chung, C. B., 2001a, Dynamic Modeling and Simulation of a Fluidized Catalytic Cracking Process - Part I: Process Modeling. Chemical Engineering Science, Vol. 56, No. 5, pp. 1951-1971.

Han, I. S. and Chung, C. B., 2001b, Dynamic Modeling and Simulation of a Fluidized Catalytic Cracking Process - Part II: Property Estimation and Simulation. Chemical Engineering Science, Vol. 56, No. 5, pp. 1973-1990.

Kunii, D. and Levenspiel, O., 1996, Circulating Fluidized-Bed Reactors. Chemical Engineering Science, Vol. 52, No. 15, pp. 2471-2482.

Lasarin, M. A., 1997, Modeling and Simulation of a FCC Converter Unit (Modelagem e Simulação da Seção de Conversão de uma Unidade FCC). PhD Thesis, UNICAMP Department of Chemical Engineering. Campinas, SP, Brazil: (in Portuguese).

Lee, L. S., Yu, S. and Cheng, C., 1989, Fluidized-Bed Catalyst Cracking Regenerator 
Modelling and Analysis. The Chemical Engineering Journal, Vol. 40, pp. 71-89.

Levenspiel, O., 1998, Chemical Reaction Engineering. John Wiley and Sons Inc.

Malay, P., Milne, B. J. and Rohani, S., 1999, The Modified Dynamic of a Riser Type Fluid Catalytic Unit. The Canadian Journal of Chemical Engineering; Vol. 77, pp. 169-179.

McFarlane, R. C., Reineman, R. C, Bartee, J. F. and Georgakis, C., 1993, Dynamic Simulator for a Model IV Fluid Catalytic Cracking Unit. Computers \& Chemical Engineering, Vol. 17, No. 3, pp. 275300 .

NACS. Eger Murphree and the four Horsemen: FCC, Fluid Catalytic Cracking, The North American Catalysis Society, 2003. See also: http://www.nacatsoc.org.

Patankar, S. V., 1980, Numerical Heat Transfer and Fluid Flow. New York: Hemisphere Publishing Corporation.

Santos, M. G., 2000, Dynamic Model for Control of a UOP FCC Unit (Modelo Dinâmico para o Controle do Conversor de uma Unidade de FCC UOP STACKED). MSc Thesis, UFRGS Department of Chemical Engineering, Porto Alegre, RS, Brazil (in Portuguese). 